\title{
El retrato en los primeros cartelistas españoles de cine: De la escena costumbrista al retrato realista
}

\section{The portrait of the first poster artists of Spanish cinema: From the genre scene to the realistic portrait}

\author{
MARÍA T. MORALES-CARRIÓN \\ Universidad de Granada. \\ marytriny89@hotmail.com
}

Recibido: 21 de febrero de 2014

Aprobado: 12 de junio de 2014

\begin{abstract}
Resumen
El artículo, que forma parte de un trabajo más amplio, pretende resaltar el uso del retrato en los carteles de cine de los primeros cartelistas españoles antes de que se implantase el star-sytem en España. Para ello se describe la evolución que se produce en la representación de los personajes en los carteles de cine desde los años diez hasta el inicio de los treinta del siglo XX, período histórico de profundas influencias de las vanguardias artísticas y publicitarias en las obras de nuestros cartelistas. Sin embargo, a finales de los años veinte se pasa de la simple inclusión de una escena, basada en un fotograma de una película, a la representación cromática y realista del rostro de la estrella, justamente en los años en los que comienza a notarse la influencia de los grandes estudios norteamericanos en España. No obstante, destacan su libertad técnica y compositiva, y la influencia que ejercen sobre los cartelistas posteriores ya que muchos de ellos integrarán los retratos y ambientaciones en sus carteles, siguiendo las directrices de los grandes estudios o los estudios independientes: o sea, los estudios en general, pero sin abandonar su forma personal de pintar los rostros de las estrellas de cine.
\end{abstract}

Palabras clave: cartel de cine, escena costumbrista, realismo en el retrato, sistema de estudios, años veinte.

Morales-Carrión, M.T. (2015): El retrato en los primeros cartelistas españoles de cine: De la escena costumbrista al retrato realista. Arte, Individuo y Sociedad, 27(1) 117-131

\begin{abstract}
The article, which is part of a more detailed piece of work, aims to highlight the use of the portrait on the film posters of the first Spanish poster artists before the Star-System was introduced in Spain. For this it is posed the evolution that occurs in the representation of the characters in the film poster from the second decade to the beginning of the thirties in the twentieth century, a historical period of profound influences of the artistic and advertising vanguards in our poster artists' work. However, in the late twenties moving from the simple inclusion of the scene based on the picture of a film, to the chromatic and realistic representation of the star's face. These were the years when the influence of the major North American studios began to show in Spain. Nevertheless, it highlights their technical and compositional freedom and their influence on subsequent poster artists, as many of them will integrate the portraits and settings on their posters, following the guidelines of the major studios or the independent ones. But without forgetting their own personal way of painting the film stars' faces on their posters. Keywords: film poster, genre scene, realism in the portrait, studio systems, the twenties.
\end{abstract}


Sumario: 1. Introducción, 2. El cartel de cine de 1910 a 1920, 3. Años veinte: De la escena costumbrista al retrato personalizado en el cartel de cine, 4. El retrato de los cartelistas españoles en los inicios del star-system, 5. Conclusiones. Referencias.

\section{Introducción}

Los carteles que anunciaban las primeras proyecciones cinematográficas en España durante los últimos años del siglo XIX y la primera década del XX, no se diferenciaban mucho de los que se usaban para dar a conocer cualquier otro espectáculo del momento. Su diseño era en casi todo muy parecido al que se hacía para anunciar las corridas de toros, las atracciones de feria o cualquier obra de teatro. Sánchez (1996:143), en relación a los primeros locales de proyección ya fijos en Zaragoza, destaca que "Estos y los locales feriales con los que convivían tenían carteles llamativos y de colores chillones, semejantes a los de cualquier otra atracción ferial".

Sin embargo, estos primeros carteles eran escasos y con poca difusión, debido a que la incipiente industria cinematográfica carecía de suficientes apoyos económicos, institucionales y privados. Cuestiones a las que se le añadieron su debilidad técnica, con películas de corta duración que formaban parte de programas mixtos, y su falta de proyección al exterior, lo que se tradujo a su vez en una producción incierta y poco constante que afectó tanto a la producción de los filmes como a la de su propaganda.

Baena (1996a:13), refiriéndose a esta misma cuestión, resalta que:

El cartel de cine de los inicios siguió unos derroteros de escasa ventura y fertilidad, al no contar con ni una sola circunstancia propiciatoria, aunque, en realidad, todas las vicisitudes por las que pasó fueron siempre consecuencia de la endeblez económica y técnica de nuestro cine, frente a la robustez del foráneo".

A los factores anteriores había que añadir el hecho de que, al ser las películas de corto metraje, se juntaban varias para ser proyectadas en una misma sesión, lo que hacía casi imposible elaborar un cartel distinto para cada una. Asimismo se daba una gran pobreza técnica en su confección, ya que se recurría al cartel tipográfico que contenía una fotografía monocromática de alguna escena del film en lugar del litográfico que le podría haber dotado de una gama de tintas más amplia y otorgado mayores posibilidades y complejidad a la composición.

En este marco se ha situado nuestro estudio, que exploraba la relación entre el uso del retrato de carácter plástico en el cartel de cine y la publicidad cinematográfica, centrándose el análisis en el primero y no en el segundo. Es por ello que estamos ante un estudio artístico y no comunicacional.

Por todo lo cual, en este estudio nos hemos planteado la observación de los carteles de cine correspondientes a este periodo histórico bajo la hipótesis de que algunos de los cartelistas españoles de los años veinte ya incluían el retrato de la estrella en sus carteles de cine mucho antes de que se lo exigieran los Grandes Estudios de Hollywood.

En este artículo exponemos únicamente la evolución de este recurso artístico en los cartelistas españoles, llegando a la conclusión de que fue en esta época donde se sentaron las bases del retrato plástico en el cartel de cine que más tarde seguirían los grandes cartelistas españoles de postguerra. 
Del planteamiento de nuestra hipótesis necesariamente se derivaban los siguientes objetivos:

- Estudiar las características técnicas y formales de los retratos realizados por los cartelistas españoles en los carteles cinematográficos de 1920 a 1930.

- Obtener una visión general de la evolución del retrato en el cartel de cine realizado por la generación de cartelistas españoles de los años veinte.

- Servir de base documental y teórica para futuros trabajos sobre esta temática.

- Sensibilizar sobre esta forma de comunicación visual de carácter artístico y cultural hoy casi olvidada.

Por consiguiente, el diseño de nuestra investigación ha sido esencialmente cualitativo, ya que se ha centrado más en los aspectos técnicos y plásticos del retrato en el cartel de cine que en la cantidad de obras y autores que lo han puesto en práctica.

\section{El cartel de cine de 1910 a 1920}

A partir de 1910 la situación comenzaba a mejorar y se podían apreciar ya carteles totalmente desligados de los otros espectáculos, con información propia, y en los que la figura humana cobraba significado en relación con el argumento de la película. Eran carteles en los que predominaba el plano de conjunto de los personajes en medio de una escena ambientada en el film.

Así, encontramos carteles como el de la película Locura de amor (1909), de Ricardo de Baños y Alberto Marro, realizado por Affiches Barral, en el que se representa a la reina Doña Juana de cuerpo entero, de pie, en posición de tres cuartos en la parte derecha del cuadro, contemplando el féretro de su esposo muerto. La escena, cargada de dramatismo, está resuelta con una composición y técnica que son propias del realismo pictórico de finales del siglo diecinueve. Su estilo nos podría recordar al empleado por el pintor Francisco Padilla en su cuadro de Doña Juana la Loca (1877).

En esta misma línea se encuentra también el cartel de la película Don Pedro I (1911), también dirigida por Ricardo de Baños y Alberto Marro, firmado por el pintor Pére Montanyá, en el que se puede apreciar ese estilo pictórico. Para este cartel, Montanyá elige una escena significativa del film con tres personajes y gran teatralidad. De tal modo, en un formato horizontal, pinta tanto a estos personajes como al espacio interior, con fuertes contrastes de luz y sombra y acompañados de reflejos rojos que, junto al amarillo pálido de las zonas iluminadas y el gris y negro de las oscuras, contribuyen a resaltar el dramatismo del instante escogido.

También en 1912, el valenciano Carlos Ruano Llopis realiza en esta misma línea pictórica el cartel del film francés La torre de Nesle (1912) (Ilustración 1), pero ahora situando a los personajes en un jardín, con menor realismo y mayor colorido.

Desafortunadamente, de este tipo de carteles hoy no quedan muchos ejemplares realizados antes de 1920 en los que, como en los anteriores, se utilizase el dibujo y el color en la representación de los filmes a los que hacían referencia, ya que en la confección de la gran mayoría se recurría a la fotografía coloreada, y el resto se ha visto abocado a la desaparición debido a las dificultades que entrañaba su conservación. Pues, como resalta Sánchez (1996:145): "Ya en los primeros años hay un buen número de reclamos cinematográficos que prefieren la fotografía". 


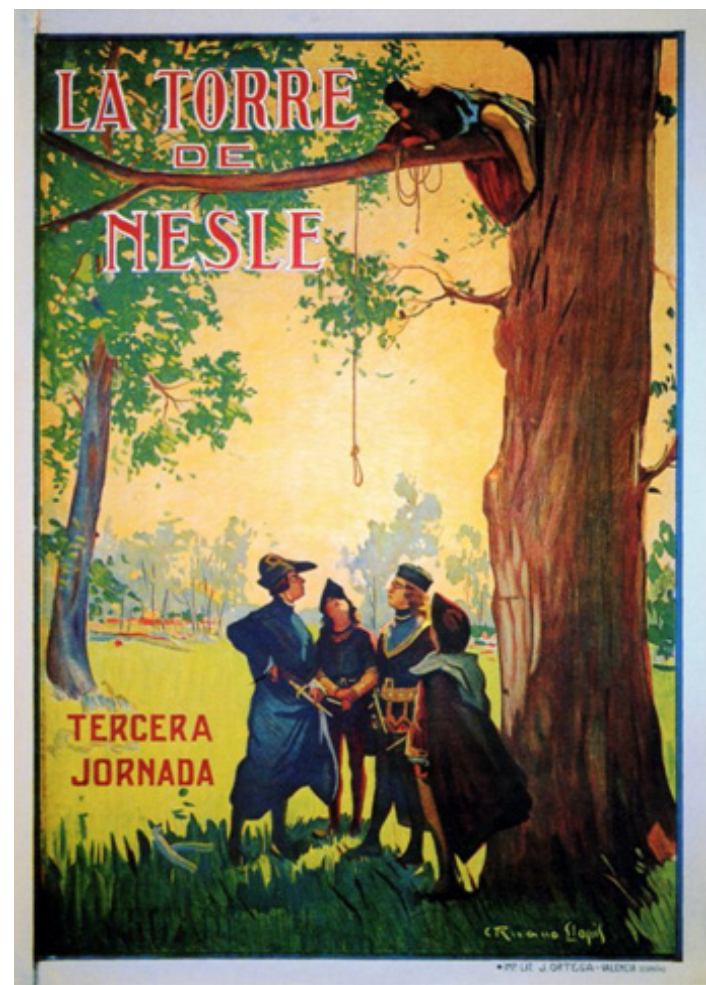

Ilustración 1. La Torre de Nesle, 1912, cartel de Carlos Ruano LLopis.

Fuente: http://www.fundaciondoctordepando.com/CINE-CARTELES/1912

Por otra parte, como apunta Baena:

No será hasta la década de los veinte cuando el cartel de cine comience una andadura que si no del todo uniforme, establecerá las bases de un futuro que se adivine cercano. Hasta ese momento, la mayoría de los carteles que engalanaban las fachadas de los coliseos eran producidos fuera de nuestro país y en el idioma original de la película, algo que, salvo excepciones, se mantendría hasta bien entrada la década en este tipo de producciones foráneas" (1996b:34).

\section{Años veinte: De la escena costumbrista al retrato personalizado en el cartel de cine}

Más adelante, en los años previos a 1920, con la proliferación de salas dedicadas exclusivamente a la proyección de películas, el aumento del tiempo de metraje en los filmes y el apoyo de las productoras nacionales al cine autóctono se produjo un auge en la confección de carteles que anunciaban dichas proyecciones. Esto contribuyó a que los carteles cobrasen cierto carácter gráfico y plástico, con imágenes más coloristas -gracias a la reproducción litográfica- y en las que el dibujo, las escenas costumbristas y la representación de alguno de los personajes, extraídos de alguna secuencia del film, jugaran un papel importante en los mismos. 
Entre los artistas que representaban esta línea costumbrista destacó el valenciano J. Estrems, gran dibujante y buen conocedor del color y de la técnica litográfica. Entre sus trabajos más destacados se encuentra el cartel de Gigantes y cabezudos (1926). En este cartel, Estrems representa de pie a los personajes del film, en un gran plano de conjunto a modo de panorámica cinematográfica, cogidos de la mano y colocados en una hilera decreciente que abarca toda la zona central del mismo, siendo éste un recurso que se generalizará más adelante. Además del colorido, aplicado con gouache a base de aguadas de color, a modo de acuarelas, y la perfección del dibujo, cabe resaltar que el segundo personaje es un retrato de la actriz Carmen Viance (Ilustración 2), colocada justamente bajo su nombre y, aunque aún no se puede hablar del efecto del star-system en los afiches españoles, sí se puede considerar un buen precedente ya que en este cartel se reconoce a la estrella femenina.

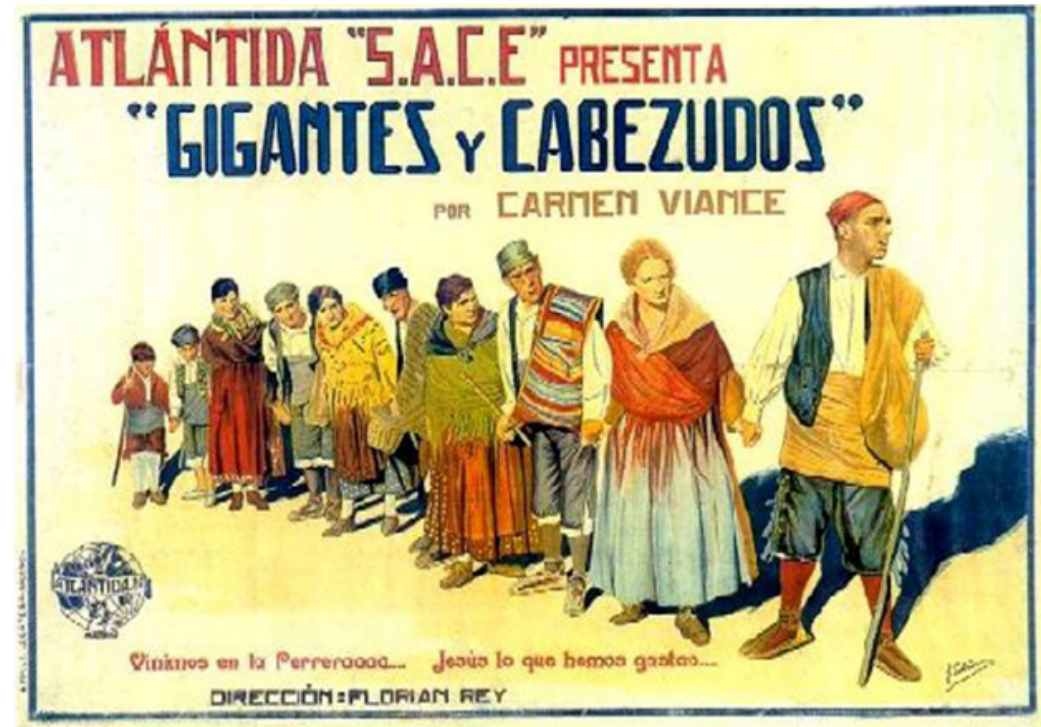

Ilustración 2. Gigantes y cabezudos, 1926, cartel de J. Estrems.

Fuente: http://www.fundaciondoctordepando.com/CINE-CARTELES/1926

El otro cartel costumbrista de Estrems Por un milagro de amor, también del mismo 1926, contiene una escena del film en la que se puede reconocer la huerta levantina, con la barraca, los naranjos y las palmeras como escenario y a los personajes del drama romántico César Mairena, Duque de Mairena, que está sentado en la puerta observando a su amante Valentina Zárate "la loba" mientras ésta cose un paño. En este caso no se acredita en el cartel a los actores Josefina Tapias ni Fernando Díaz de Mendoza, pero se pueden reconocer sus rostros en los dos personajes pintados.

Otros dos trabajos de Estrems que reflejan escenas cotidianas son los de las películas Rosa de Levante y Carmiña flor de Galicia, ambas de 1926. En el primero se aprecia la gran maestría de Estrems en la ambientación del campo de naranjos y la distribución de los personajes, destacando en la parte superior la participación de la estrella cinematográfica nacional Carmen Viance. En el segundo, Estrems pinta el interior de un restaurante con la pareja de actores principales sentados a la mesa y el camarero 
al fondo. Ambos son carteles que están pintados con la técnica de pigmentos al agua, acuarelas y gouache, que permiten otorgar a las escenas de un realismo mágico lleno de color y luminosidad.

Otro cartelista que realizó sus trabajos de propaganda cinematográfica en esta década, centrándolos en el dibujo de personajes y escenas ambientadas de las películas del momento, fue Joaquín García Moya. De hecho, en algunos de sus carteles se apreciaban ya intentos de incluir las facciones de los actores de los filmes en los mismos, lo que le incluye en esa primera lista de cartelistas precursores del retrato en el cartel cinematográfico de la siguiente década.

Así, en el cartel de la película Los granujas (1924), (Ilustración 3) Joaquín construye la composición con tres personajes de pie, en posición de tres cuartos, ocupando la parte central del cartel y sobre un fondo neutro resuelto con superficies de color discontinuas, con la única separación del suelo y del fondo delimitada por una suave variación tonal y cromática, más amarillenta en la parte superior y de color siena en el suelo. Este tipo de fondo se verá desarrollado algunas décadas más tarde en los carteles de comedias realizados por Jano y Fernando Albericio, entre otros.

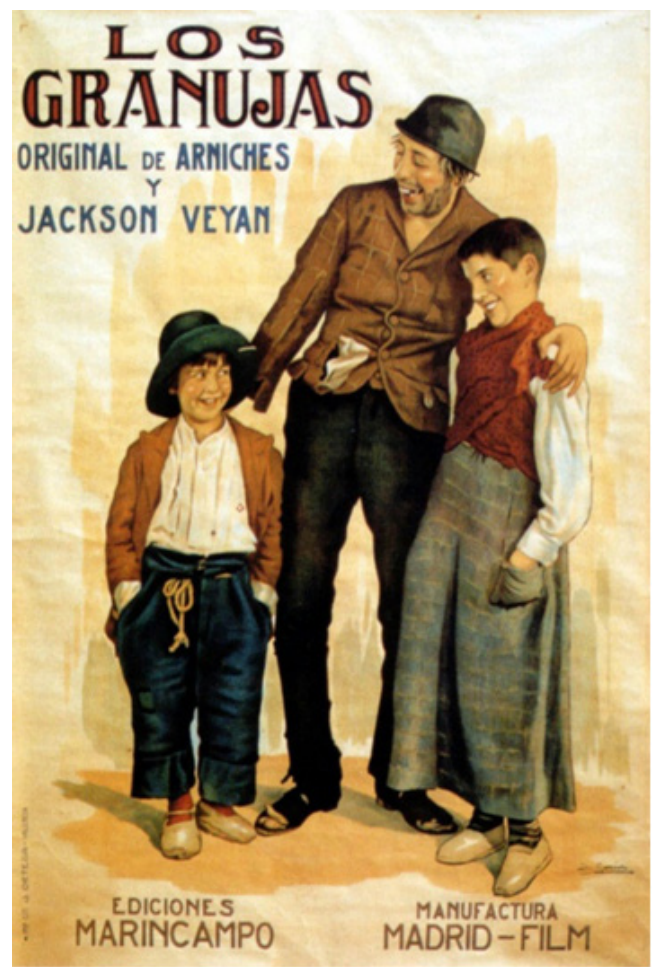

Ilustración 3. Los granujas, 1924, cartel de Joaquín García Moya.

Fuente: http://www.filmweb.pl/film/Los+Granujas-1924

Otro aspecto a destacar en este dibujante es la integración de los personajes en el cartel a través de la complicidad comunicativa de sus miradas. 
En tercer lugar es destacable su habilidad para el retrato de los niños en este cartel de cine. Uno de ellos, el de la izquierda y el más pequeño, es el joven actor Alfredo Hurtado "Pitusín". Joaquín pinta a los niños de barrios marginales y de la calle que aparecen en estas películas, con especial maestría, siguiendo esta misma línea temática tratada por la cinematografia internacional del momento.

En esa misma línea representativa de carteles en los que se incluyen niños mendigos o pícaros, se encuentra el retrato que Joaquín realiza también de "Pitusín" en el cartel de El Lazarillo de Tormes (1925), en el que también se retrata a la estrella femenina del momento Carmen Viance, con peculiar estilo colorista, lleno de colores brillantes y luminosos y en el que, como en la mayoría de sus obras, remarca los contornos de ambos personajes con un halo luminoso, otorgándoles una apariencia mágica y sobrenatural.

En el cartel de La condesa María (1927), Joaquín coloca a la pareja de actores Rosario Pino y José Nieto de pie, con Rosario a la izquierda levemente inclinada hacia éste, siendo ésta una forma de posicionar a la pareja de amantes que será repetida por numerosos cartelistas españoles en décadas posteriores. El cartel, sin salirse de la línea estilística de Joaquín, contrasta con el realizado para la proyección de esta película en Francia por Mercier, pues en éste el cartelista francés realiza dos bustos de ambos personajes, con el masculino en la parte izquierda acercando su rostro al de la actriz, y los hace acompañar de escenas con parejas bailando tras ellos. Sin embargo, lo resuelve todo con un estilo más cercano al art deco o modernismo tardío que al realismo pictórico, con figuras y colores más planos que los de Joaquín.

A lo largo de esta década, otro de los cartelistas más prolijos de la misma fue César Fernández Ardavín, pintor y cartelista, perteneciente a la familia de litógrafos madrileños Litografías Fernández.

En el seno de esta empresa de la familia Fernández Ardavín, el joven César conoció de primera mano las tendencias de la publicidad del momento y se inició en este arte del cartel de cine desde muy joven. Realizó los carteles de las películas de su hermano Eusebio y firmó algunos trabajos con su nombre completo, aunque más tarde lo haría con el seudónimo de "Vinfer".

Rodríguez (2004:27) resalta que:

El interés por la litografía y el cartel no sólo le vino por motivos familiares. Al igual que muchos pintores, Ardavín vio en esta técnica infinitas posibilidades expresivas donde poder volcar todos sus conocimientos como pintor. El diseño de carteles, dibujar directamente sobre la piedra o la plancha, supuso para él aunar su capacidad plástica con el oficio de litógrafo, que conocía a la perfección.

Ardavín, desde muy joven destacó en la pintura como buen conocedor del color, el dibujo y el retrato, llevando a cabo su labor como cartelista de cine y otros espectáculos desde principios de siglo hasta los años treinta.

Es también uno de los que mejor ha representado la figura humana en los carteles de cine desde muy joven. Rodríguez (2004:26) afirma que: "Sus primeras creaciones están marcadas por un tono costumbrista, pero dotadas al mismo tiempo de una gran carga social que le revelan como un gran retratista". Estas cualidades le llevan a realizar carteles de películas a inicios de los veinte como los que hace para los filmes ¡Cuidado con los ladrones! (1919), La verbena de la paloma (1921) (Ilustración 4) y La revoltosa 
(1924), en los que ya se puede apreciar su habilidad para la composición y el retrato. Son carteles que representan a los personajes en planos medios, con una gran carga cromática, ocupando los dos tercios o la parte superior del cartel y dejando el resto libre para la información textual, poniendo ya de manifiesto su madurez artística.

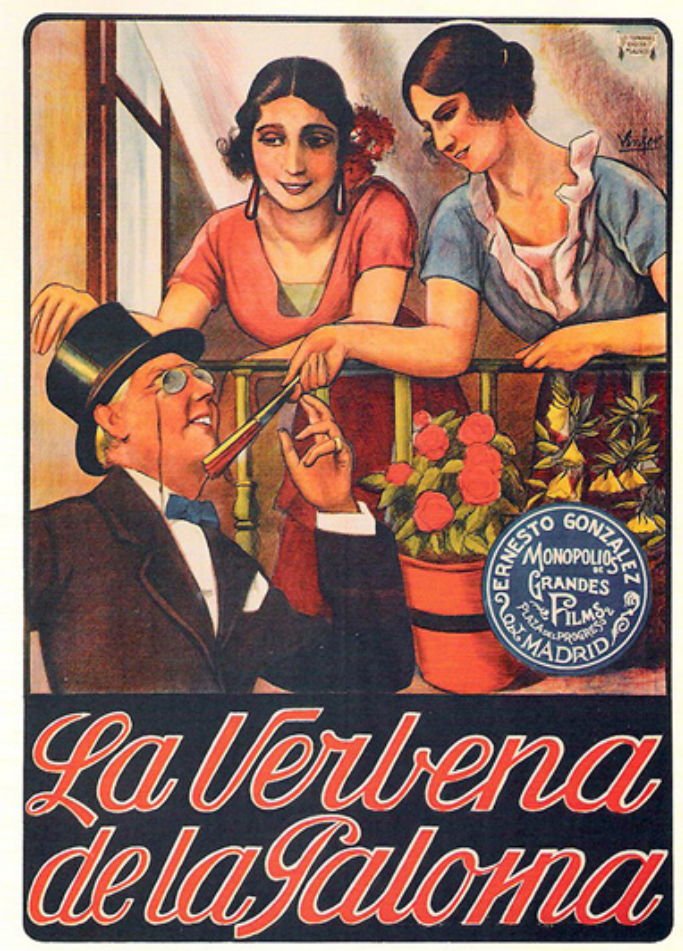

Ilustración 4. La verbena de la Paloma, 1921, cartel de César Fernández Ardavín (Vinfer).

Fuente: http://www.encadenados.org/rdc/silencio-es-oro/59-galeria-fotografica/2520

Los carteles que Joaquín García y César Ardavín diseñan para la película Más allá de la muerte, basada en la novela de Jacinto Benavente y dirigida por Benito Perojo (1924), suponen ya un anticipo del cambio de tendencia en la representación de los personajes y las escenas de los filmes, pues aunque en el de Joaquín todavía se aprecie algún rasgo costumbrista, con la pareja representada con un plano medio sobre un fondo ambientado, en los dos de Vinfer se denota ya una clara tendencia a ubicar el cuerpo y el rostro humano en la parte central del cartel sobre un fondo neutro. Para ello coloca, en el primero, el personaje femenino guardando un revólver en un bolso de mano, y en el segundo pinta el enorme rostro del protagonista masculino ocupando todo el cartel.

Ese conocimiento y dominio del dibujo y de la técnica litográfica, le permiten a Vinfer jugar con ventaja para continuar confeccionando composiciones de gran belleza y realismo en la segunda mitad de los años veinte. En Ardavín: 
Encontramos diseños con tratamientos claramente pictóricos, junto a otros donde se percibe una asimilación plena de las técnicas del cartel. El dominio del color, utilizándolo como elemento dramático y como mancha que reemplaza los diferentes términos espaciales; la reinterpretación estilizada de los motivos fotográficos (...) A todo habría que añadir lo que él consideraba uno de sus principales hallazgos: hacer del rostro humano motivo central del cartel y trabajarlo a gran escala de manera que se convierta en su principal baza interpretativa (Rodríguez, 2004:28).

En este sentido, cabe resaltar que, aunque los carteles españoles de los años veinte hiciesen referencia casi en exclusiva a las películas nacionales y a los actores que las protagonizaban, no estaban tan alejados de la concepción que Hollywood tenía del retrato de sus grandes estrellas cinematográficas a través del star-system a finales de esta misma década. Ya tanto César Ardavín como otros cartelistas españoles, estaban haciendo uso de ese recurso, aunque sin las estridencias de Hollywood ni con el reparto tan equilibrado de los diversos componentes del mismo.

Así encontramos retratos de bustos de los personajes, ocupando todo el espacio del cartel, tanto el del actor Raymond Sarka, en el cartel que Ardavín hace para El negro que tenía el alma blanca (1927), como el de la actriz Carmen Rico en el que Joaquín diseña para la película Mientras la aldea duerme (1926).

Según Baena (1996b:39): "Hay que diferenciar entre dos lenguajes de carácter antagónico: los carteles que daban cobertura a las producciones nacionales y los que hacían lo propio con las foráneas, especialmente las de Hollywood", aunque ante la consideración de los carteles de esta década como parte de un posible star-system español, considera que: "Los actores nacionales no poseían el suficiente crédito y notoriedad -tampoco nuestro cine- como para poder equipararse a los creados por el laboratorio americano del starsystem, de manera que los carteles raramente basaban su mensaje en sublimar su figura".

Sin embargo, Rodríguez (2004:32), haciendo referencia a esto, destaca que: "El recurso al rostro, a su fuerza fotogénica como elemento central de la composición del cartel será uno de los procedimientos predilectos de Ardavín, en el que volverá a dejar su impronta de gran retratista".

Ardavín es un buen fisonomista, al que le gusta, como apunta Fernández (2004: 30): "dibujar rostros grandes de mujer. Porque no había entonces nada que atrajera tanto a un espectador como un rostro humano". Prueba de ello es el retrato que realiza de Conchita Piquer, en el cartel promocional de la película El negro que tenía el alma blanca (1927) (Ilustración 5). Dibuja y pinta un primer plano de la actriz con los hombros en posición de tres cuartos y el rostro de frente y aire melancólico, con un punto de vista bajo que le da realce y majestuosidad a la actriz que porta una peineta de perlas en la cabeza, al mejor estilo modernista. Todo dibujado y pintado sobre un fondo neutro con una resolución técnica impecable.

Con fondos neutros y de tonalidad oscura realiza también varios carteles en 1927 , destacando entre otros el cartel que hace para Los aparecidos, una adaptación al cine de la obra de Arniches y Lucio. En el lateral izquierdo representa a José Montenegro, protagonista de la película con turbante y traje blancos, subido en un asno, de frente sobre un fondo oscuro que invade todo el cartel pero dejando la parte superior para el título y la inferior derecha para la información textual. Con la misma factura pero 
con formato horizontal y sobre un fondo azul ultramar oscuro realiza también el cartel de Rosa de Madrid, con las actrices Conchita Dorado y Carmen Toledo - claramente reconocibles -, sonrientes y subidas en los caballitos de un tiovivo.

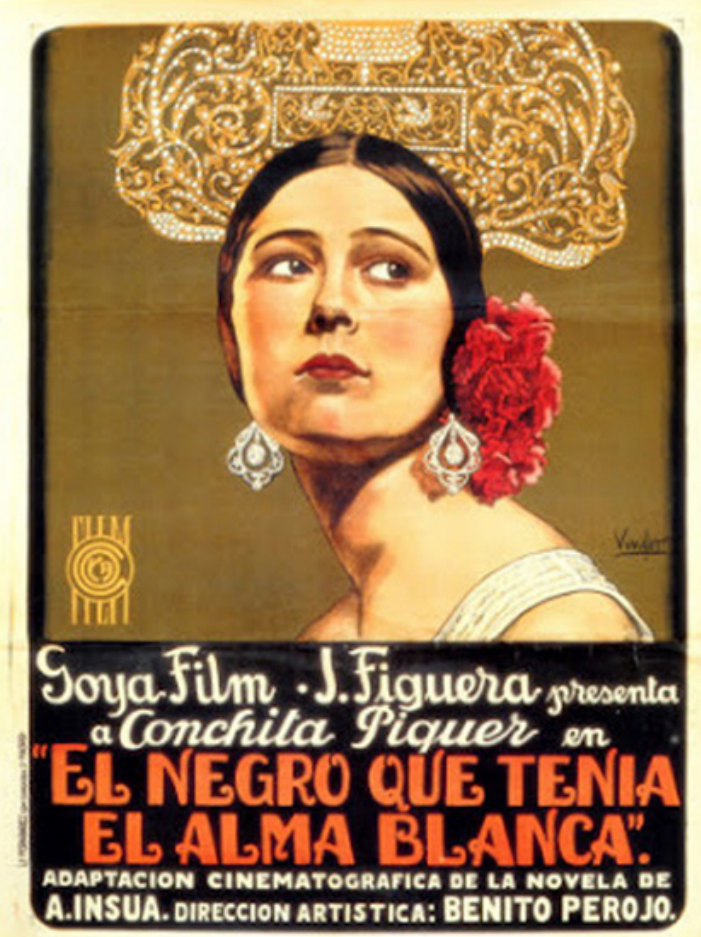

Ilustración 5. El negro que tenía el alma blanca, cartel de César Fernández Ardavín (Vinfer). Fuente: http://ricardotecela.blogspot.com.es/2012/04/benito-perojo-filmografia-director.html

Sin embargo, lo más destacable de esta última etapa de César son los carteles que realiza para la película alemana Se cruzó en mi camino (Der Meister der Welt, 1927, Gennaro Righelli). Uno de ellos con una escena del film y el otro con la imagen de la protagonista en solitario. En ambos Ardavín realiza un excelente retrato de la actriz Olga Tschechowa, destacando en el que aparece la estrella en posición de tres cuartos con gesto de pose - muy propio del star-system - que se ve reforzado por la inclusión de su nombre en la parte inferior del cartel, bajo el título del film.

Ardavín ya había realizado en su etapa temprana otros carteles para películas extranjeras, unos con composiciones más simples y otros un poco más complejas, con una o dos tintas o con una paleta más rica en color, pero siempre con predominio del dibujo sobre la gama cromática. De entre ellos destacan:

1) Los carteles realizados para películas americanas como el de Armas al hombro (Shouldermans, 1918, Charles Chaplin), con un excelente primer plano colorista de Charles Chaplin portando una cartela de invitación y presentación de la película en dos cines; el de El hombre del misterio (Theman of Mystery, 1917, Frederick A. Thomson), 
con el primer plano del rostro masculino pintado de color sanguina e inscrito en un triángulo blanco invertido sobre un fondo también rojizo o el de El farol rojo (The red Lantern, 1919, Albert Capellán), con una bailarina dibujada de perfil con los brazos levantados, realizada con tonos sepia sobre fondo rojo.

2) Los afiches pintados para las películas italianas como el de Los misterios de París (Parigi misteriosa, 1917, Gustavo Serena), con el dibujo de un grupo de personajes, realizado con tonos sepia sobre el fondo oscuro de la ciudad, o el de Frou-Frou (FrouFrou, 1918, Alfredo de Antoni) con el dibujo en escala de grises de la pareja sobre fondo rojo.

3) Los carteles diseñados para las películas francesas como el de El pensador (Le penseur, 1920, Léon Poirier) y Los tres mosqueteros (Les trois mousquetaires, 1921, Henri Diamant-Bengee).

En el cartel de El pensador dibuja a los personajes siguiendo una diagonal, con planos medios, en tres cuartos, de perfil y con claroscuros para darle a la escena una carga más dramática; mientras que, en el de Los tres mosqueteros, presenta los bustos de los tres personajes alineados horizontalmente y ocupando toda la parte central del cartel, con los dos de los laterales de perfil y el del centro de frente.

A pesar de que en los años veinte se apoyaba a la cinematografía nacional en pro de la creación -sobre todo en la segunda mitad de la década- del star-system español, financiando la publicidad de sus propias producciones cinematográficas y estrellas, hubo cartelistas que como Ardavín realizaron carteles para la promoción de películas extranjeras. Joaquín García lo hizo también de forma muy temprana con sus carteles para la película Tarzán de los monos (1920). Sin embargo, la gran mayoría de los carteles y programas de mano eran anónimos, como los que se hicieron para dar a conocer las películas de El capitán Blood (1924), 3 hombres malos (1926) o El zeppelín perdido (1929), muchos de ellos con predominio del dibujo y las tintas planas.

Hubo a lo largo de esta década también una larga lista de cartelistas que trabajaron la figura humana en el cartel, que iban desde los que mantenían la tendencia pictórica costumbrista a los que incorporaban las vanguardias en sus trabajos.

De los primeros destacan Sánchez Dubón Guasp con el cartel de La bruja (1923) y C. Ruano Llopis con Los chicos de la escuela (1925), entre otros.

A caballo entre el realismo pictórico y el modernismo encontramos el cartel de Nobleza baturra (1926), de León Astruc, en el que se aprecia ya el intento de combinar el retrato de la joven intérprete Inocencia Alcubierre, sentada en posición de tres cuartos, con una calle de la ciudad como fondo. También cabe destacar dentro de este estilo realista, los carteles que realiza Tristán para la película Boy (1926), de gran expresividad gráfica y plástica.

De la segunda tendencia, destacan los dibujantes del momento que incorporan las técnicas introducidas por las vanguardias, como el art nouveau o el constructivismo entre otras, pero siempre sin alejarse de las representaciones figurativas y realistas. La figura humana sigue siendo el reclamo más apreciado por estos artistas, pudiéndose acercar de forma tímida en algunos casos al retrato. Algunos de ellos son Gago y Palacios con sus carteles de películas españolas como El cura de la aldea (1926) y El patio de los naranjos (1926) o el retrato que hace de la actriz Raquel Meller en el cartel de la película francesa La venenosa (1928); Rafael de Penagos, con sus carteles de La 
hermana San Sulpicio (1927) y Agustina de Aragón (1929), de gran carga expresiva; Salvador Bartolozzi con El bandido de la sierra (1927) y Zalacaín el aventurero (1929). Todos realizados con una técnica postmodernista, en la que predominan las tintas planas y el dibujo, más cercanos a la simplificación de la imagen que al retrato figurativo con tendencia al realismo pictórico.

\section{El retrato de los cartelistas españoles en los inicios del star-system}

A finales de la década comenzaron a instalarse las productoras extranjeras en España, sobre todo las norteamericanas, con su empeño de promocionar el star-system, -un nuevo sistema de diseño del cartel de cine basado en el culto a la imagen y la publicidad de la estrella de Hollywood- imponiendo sus propios criterios de creación y estética. Irrupción que acabaría con este período de libertad creativa, ya que la gran mayoría de los cartelistas de la década habían seguido sus propias técnicas y criterios compositivos que habían dado lugar a una gran época dorada del retrato en el cartel de cine. Pues, como afirma Baena (1996b:40):

El liberalismo artístico que se dio en esos años en la concepción de algunos carteles de producción autóctona no tuvo parangón en ninguna otra etapa del cartelismo cinematográfico español. No se puede hablar de escuelas ni de moda. Ninguno de los grandes siguió a nadie. Cada creador trató de imponer su estilo, su trazo, aunque como hemos dicho su ensoñadora aportación al cine tuviera un repentino despertar.

La instalación de los grandes estudios norteamericanos en el mercado publicitario español provocó que parte de sus carteles, que hasta ese momento habían sido confeccionados por cartelistas foráneos, comenzasen a ser producidos por nuestra industria. Entre los más tempranos destacaron "los editados bajo los sellos de Los Artistas Asociados e Hispano Foxfilm, entre otros" (Baena, 1996b: 37).

Un claro ejemplo de esto son los carteles de La fierecilla domada y La máscara de hierro (1929), (Ilustración 6). En el primero ya se aprecia la impronta del star-system, con el nombre de las dos estrellas en la parte superior y su retrato en plano de conjunto, ocupando toda la superficie del cartel, aunque todavía se representa una escena del film.

Sin embargo, en el segundo ya se apuntan las líneas más generales y comunes de este nuevo sistema compositivo. En ese cartel aparece el busto de la estrella Douglas Fairbanks como fondo tras una escena de los mosqueteros, representados con un plano de conjunto en la parte inferior derecha, mientras que el nombre de Fairbank y el del film se ubican bajo la misma. Todo está resuelto con una brillante gama cromática, propia de este género de intriga y espada. 


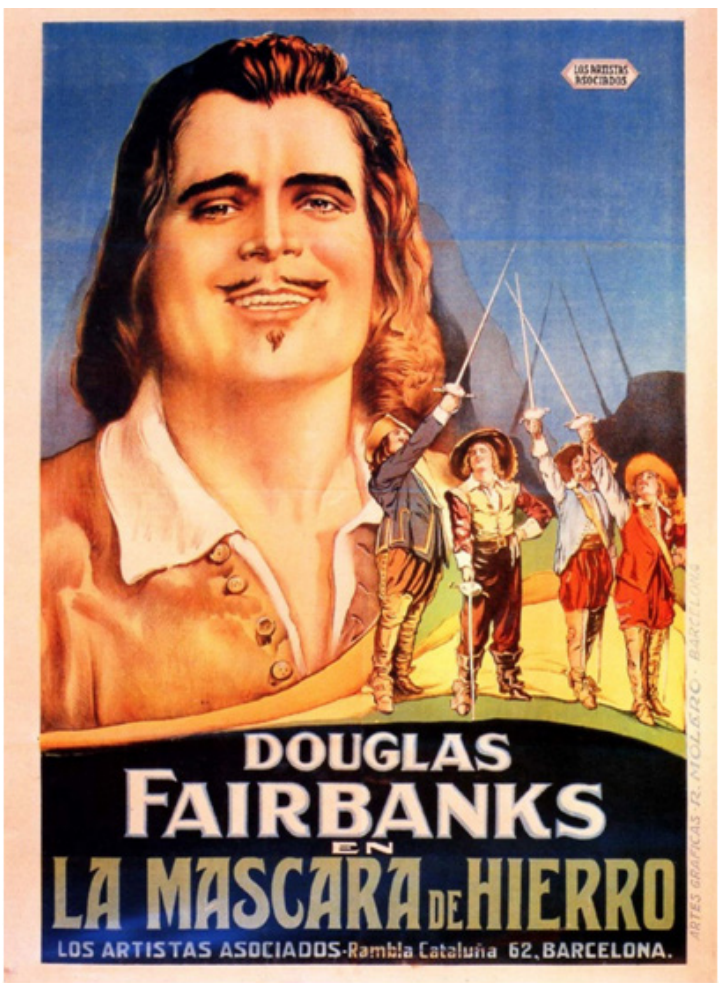

Ilustración 6. La máscara de hierro, 1929, cartel de Los Artistas Asociados.

Fuente: http://www.com-mon.com/estados-unidos/1929/la-mascara-de-hierro.html

Esta influencia de los grandes estudios norteamericanos en los cartelistas también se deja ver en el cartel que en 1928 realiza César Fernández Ardavín para la película Colorín, de Adolfo Aznar, en el que, como en los dos anteriores de los Artistas Asociados, destaca el nombre de la estrella española Dina Montero en la parte superior. Pero en este caso, a diferencia de lo que se solía venir haciendo, crea una composición novedosa, con la ciudad como fondo y el retrato de la actriz de perfil con el pájaro en la mano, dejando el título y el nombre del director en la parte inferior del cartel.

Sin embargo estas influencias norteamericanas sobre los cartelistas españoles de finales de los años veinte, no sólo se hicieron sentir sobre el retrato de estilo realista, sino también sobre el retrato humorístico y caricaturesco. Se trataba de un estilo gráfico compositivo ajeno a la tradición representativa española de los personajes de los filmes, aunque el primer ejemplo de dibujo cómico y burlesco lo encontramos ya en 1915, en los trazos de los tres personajes que aparecen en un gran plano medio en el cartel anónimo de la película norteamericana Carmen (Charlie Chaplin's A Burlesqueon Carmen, de Charles Chaplin).

Los otros ejemplos los encontramos en dos carteles realizados en 1928 correspondientes a las dos películas españolas de Charlot, torero español y Ya t'oyí, ya que, según Baena (1996b:40): 
"En ambos, la figura de Chaplin adquiere protagonismo, cuando en realidad fueron sucedáneos filmados por nuestra industria que nada tenían que ver con el actor. Se trata de los únicos ejemplos encontrados hasta esta fecha, cuyo tratamiento gráfico se aparta del realismo para entrar de lleno en un estilo de trazo humorístico o caricaturesco. Están firmados por F. Martínez y Germán Horacio, respectivamente”.

\section{Conclusiones}

Con la llegada de los años treinta acabó una década de suma importancia para el retrato en el cartel de cine de los artistas españoles que supuso un gran sumario de nuevas formas de expresión gráfico-plásticas que irían más allá de los intereses publicitarios. A la libertad compositiva se unió también la gran variedad de estilos y formas de representación de la figura humana dentro del cartel. Además se establecieron algunos tópicos y modelos que más adelante se afianzarían como estables, ya que de la imagen en escenarios costumbristas, sacada de fotogramas, sobre todo para los filmes nacionales, se pasaría a la representación de los personajes con planos medios y primeros planos sobre fondos neutros en los carteles de películas extranjeras. Pero lo más significativo es que, tanto en un modelo como en otro, la fisonomía y el reconocimiento de la estrella ya se puso de manifiesto en estos artistas mucho antes de que fuesen patentados por los grandes estudios de Hollywood.

Esa libertad compositiva y estilística de los primeros cartelistas fue más allá de corrientes, escuelas o modelos a seguir. Pues, como afirma Baena (1996b:40): "Cada creador trató de imponer su estilo, su trazo" y sin pretenderlo se convertiría en un potente precedente de los grandes retratistas españoles posteriores, ya que muchos de estos nuevos artistas integrarían con maestría los retratos y ambientaciones en su carteles, bien siguiendo las líneas compositivas marcadas por el star-system, bien por los estudios independientes, pero en muchos de ellos sin renunciar a su particular forma de pintar los rostros de las estrellas en sus carteles de cine.

\section{Referencias}

Baena, F. (1994). Los programas de mano en España. (1raed). Barcelona: F.B.P. Baena, F. (1996a). Creadores y entorno.1910-1936. En Cine de papel: el cartel de cine en España. Ayuntamiento de Zaragoza, pp. 13-19.

Baena, F. (1996b). El cartel de cine en España. (1raed). Barcelona: Groucho y yo.

Barnicoat, J. (1997). Los carteles. Su historia y su lenguaje. (4raed). Barcelona: Gustavo Gili.

Brunetta, G.P. (ed.) (2011). Historia mundial del cine. Volumen primero. EE.UU. Madrid: Akal.

Checa, A. (2007). Historia de la publicidad. (1 raed). La Coruña: Netbiblo.

Fernández, C. (2004): Los carteles de Litografía E. Fernández, en AGR, Coleccionistas de Cine. Madrid: El Gran Caíd, n² 24, pp. 24-51.

Fernández, F. (2006). Nombres de mujer. Carteles de cine. Madrid: J C Clementine. Jiménez, J. (2007). StarSystem: La máquina mercadotécnica de Hollywood. En Perales, F. (ed.). Cine y publicidad. Madrid: Fragua Editorial, pp. 34-59.

Perales, F. (1999). El cartel cinematográfico. Granada: Filmoteca de Andalucía. Perales, F. (ed.) (2007). Cine y publicidad. (1raed). Madrid: Fragua Editorial. 
Pérez, J. P. (2007). Tendencias en el diseño del cartel cinematográfico: El afiche ante el siglo XXI. En Perales, F. (ed.). Cine y Propaganda. (1raed). Madrid: Fragua Editorial, pp. 165-199.

Rodríguez, R. (1996). Pintar el aura. En: Cine de papel: el cartel de cine en España. Zaragoza: Ayuntamiento (Catálogo de Exposición), pp. 21-26.

Rodríguez, R.(2005). Los Fernández Ardavín: Una saga pionera del cine. En: Carteles de cine de 1915 a 1930: Colección Fernández-Ardavín. Madrid: Filmoteca Española, ICAA, Ministerio de Cultura, pp. 19-35.

Sánchez, R. (1997). El cartel de cine: arte y publicidad. (1ra ed). Zaragoza: Prensas Universitarias.

Sánchez, V. (1995). Una cultura de la fragmentación: Pastiche, Relato y Cuerpo en el cine y la televisión. (1 ra ed). Valencia: Filmoteca Generalitat Valenciana. 